\title{
Jaw Intraosseous Lesions Biopsied Extracted From 1998 to 2010 in an Iranian Population
}

\author{
Shokoofeh Jamshidi ${ }^{1}$; Setareh Shojaei ${ }^{2, *}$; Ghodratollah Roshanaei ${ }^{3}$; Shirin Modabbernia ${ }^{4}$; \\ Esmaeel Bakhtiary ${ }^{5}$ \\ ${ }_{1}^{1}$ Dental Research Center, Department of Oral and Maxillofacial Pathology, Faculty of Dentistry, Hamadan University of Medical Sciences, Hamadan, IR Iran \\ ${ }_{3}^{2}$ Department of Oral and Maxillofacial Pathology, Faculty of Dentistry, Hamadan University of Medical Sciences, Hamadan, IR Iran \\ ${ }^{3}$ Modeling of Noncommunicable Diseases Research Center, Department of Biostatistics and Epidemiology, School of Public Health, Hamadan University of Medical Sciences, \\ Hamadan, IR Iran \\ ${ }^{4}$ Department of Oral and Maxillofacial Pathology, Faculty of Dentistry, Gilan University of Medical Sciences, Rasht, IR Iran \\ ${ }^{5}$ Faculty of Dentistry, Hamadan University of Medical Sciences, Hamadan, IR Iran \\ ${ }^{*}$ Corresponding Author: Setareh Shojaei, Department of Oral and Maxillofacial Pathology, Faculty of Dentistry, Hamadan University of Medical Sciences, Hamadan, IR Iran. \\ Tel: +98-8138354140, Fax:+98-8138381085, E-mail: s.shojaei.umsha@gmail.com
}

Received: May 25, 2014; Revised: September 3, 2014; Accepted: March 20, 2015

\begin{abstract}
Background: Jaw bones might be potential locations for different lesions. Differences in prevalence and the type of lesions can help in designing and programming prevention procedures in health care centers.

Objectives:The aim of the present study was to evaluate the prevalence of intraosseous lesions in the jaws of patients referred to diagnostic and therapeutic centers in Hamadan during 1990-2010.

Patients and Methods: This cross-sectional descriptive analytical study was carried out in Hamadan in 2011. Data sheets of the subjects were used to collect all the data of patients with intraosseous lesions, including their age, gender, location of the lesion, the radiographic view of lesions, and their type and histopathological diagnoses. Data were analyzed with SPSS, using means and frequencies.

Results: A total of 284 intraosseous lesions were reported in our study. The mean age of the subjects was $28.8 \pm 15.2$ years. The lesions were distributed in males and females almost similarly. The most prevalent lesions were cystic lesions (54.58\%), manifestations of systemic conditions in jaw bones (18.3\%), benign tumors (15.5\%), malignant lesions (6.7\%), and inflammatory lesions (4.92\%), in a descending order. The most common cystic lesion was radicular cyst; the most common manifestation of systemic conditions in jaw bones was central giant cell granuloma; the most common benign tumor was ameloblastoma; the most common malignant lesion was osteosarcoma; and the most common inflammatory lesion was periapical granuloma.

Conclusions: Our data provided information on the prevalence and types of intraosseous lesions among an Iranian population. This study provided baseline information to help in designing and programming procedures in health care centers in every community so that preventive therapeutic measures can be adopted.
\end{abstract}

Keywords: Jaw; Population; Prevalence

\section{Background}

Jaw bones and the associated soft tissues might be potential locations for different lesions, including cysts, inflammatory lesions and neoplasms with different radiographic features such as radiolucent, radiopaque and a mix of both; these lesions might be located around the tooth root, around the crown and in the inter-radicular area and they might also have no relation with teeth (1). Based on another classification, intraosseous lesions can be classified as inflammatory lesions, cysts, benign tumors, malignant neoplasms and osseous diseases found in the jaws and as the osseous manifestations of systemic conditions. Differentiation of these lesions from the normal and anatomic structures of the jaws is of particular importance and since a dentist might be the first individual to diagnose these lesions, it is very important to have a proper knowledge of the prevalence and characteristics of these lesions for diagnosis and treatment planning $(1,2)$. Retrospective studies are important for evaluation of geographic factors and variables such as gender, age and habits of individuals in a community as well as for estimation of the prevalence of such conditions in a community, because they can have a great role in identification of high-risk groups in the community and in the provision of preventive and therapeutic measures (3). In a study by Becconsall-Ryan and Love in New Zealand, 4983 radiolucent lesions related to odontogenic cysts (4), in a study by Ali (5) a total of 385 developmental/inflammatory/reactive, cystic and tumorlike radiolucent lesions, in a study by Acikgoz et al. (6), a total of 459 radiolucent lesions related to odontogenic and non-odontogenic cysts, and in a study by Varkhede et al. (7), a total of 60 radiolucent lesions related to odontogenic tumors were reported. The majority of retrospective epidemiological studies have evaluated head and neck lesions in special categories of lesions such as malignant tumors,

Copyright (C) 2015, Iranian Red Crescent Medical Journal. This is an open-access article distributed under the terms of the Creative Commons Attribution-NonCommercial 4.0 International License (http://creativecommons.org/licenses/by-nc/4.0/) which permits copy and redistribute the material just in noncommercial usages, provided the original work is properly cited. 
cysts or odontogenic tumors and some others have evaluated, in general, lesions in particular age groups.

Since sufficient data does not exist in the medical record of all the patients, including clinical history, laboratory tests, diagnostic procedures, the type of treatment and periodic follow-ups, it is necessary to carry out retrospective studies to collect the existing scattered data and transfer them to health care decision-making centers for proper programming. Therefore, there is a paucity of studies that have evaluated the general pattern of different lesions in this area. In this context, there is no comprehensive study available in Hamadan and thus, it is necessary to collect dispersed data on the subject in different diagnostic/treatment centers in Hamadan province. The results of such retrospective studies can reveal differences in frequencies, the nature of the lesions and age distribution in comparison to other studies, helping designing and programming procedures in health care centers in every community, so that preventive therapeutic measures can be adopted.

\section{Objectives}

The aim of the present study was to evaluate the prevalence of intraosseous lesions in jaws as recorded in the files of patients referred to diagnostic and therapeutic centers in Hamadan province, Iran, during 1990 - 2010.

\section{Patients and Methods}

In the present retrospective descriptive/cross-sectional study, the data sheets and radiographs of patients referring to public and private treatment centers in Hamadan, consisting of 15 public centers and four private centers equipped with pathology laboratories, from 1998 to 2010 , were reviewed by two reviewers. Kappa coefficient and $\mathrm{P}$ value were 0.95 and $<0.001$, respectively.

Data sheets of the subjects were used to collect all the data of patients with intraosseous lesions, including age, gender, location of the lesion, the radiographic view of the lesions (radiolucent, radiopaque, mixed) and their types (inflammatory, cystic, benign and malignant neoplasms, manifestations of systemic conditions and osseous diseases of the jaws) and histopathological diagnosis. During this 20-year period, of 142865 samples, 287 intraosseous lesions had been recorded. In cases in which the data was not complete on the pathology report, the required data was completed using the patient's file in the department in which the biopsy had been taken and cases without a definitive diagnosis were excluded from the study. Cases with more than one biopsy or subjects who did not have complete data such as site of lesion, gender, age, and pathological analysis were removed. The patients' data were evaluated confidentially without using the patients' names to consider ethical principles. Data were analyzed with SPSS, using means, frequencies, standard deviations and relative frequencies separately for age, gender and location of the lesion.

\section{Results}

During the 20-year period, of 142865 samples, 287 intraosseous lesions had been recorded, 284 of which were included in the study and three were excluded because they did not have complete data. Table 1 presents the frequencies of the lesions and their radiographic views. The mean age of the subjects was $28.8 \pm 15.2$ years, with minimum and maximum ages of three and 72 years, respectively. Table 2 presents the frequencies of different intraosseous lesions in terms of age and lesion type. Table 3 presents the frequencies of different intraosseous lesions in terms of gender and lesion type.

The lesions were distributed in males and females almost similarly; females $=48.8 \%$ and males $=51.2 \%$. Considering the type of lesions, the following frequency percentages were reported: $85.7 \%$ of inflammatory lesions in females; $54.9 \%$ of manifestation of osseous diseases in jaws in females; $54.8 \%$ of cystic lesions, $54.5 \%$ of benign tumors, and $57.9 \%$ of malignant lesions in males. A significant difference was observed between gender and type of lesion ( $\mathrm{P}$ Value $=0.045$ ). Regarding the frequencies of lesion locations, the lesions were found in the following locations in a descending order: posterior mandible (45.6\%), anterior maxilla (38.1\%), posterior maxilla (17.5\%), and anterior mandible (8.8\%). The majority of inflammatory lesions were located in the posterior mandible and maxilla (42.9\%); cystic lesions and benign and malignant lesions of the jaws and manifestations of systemic conditions in the jaws were found in the posterior mandible with frequencies of $34.2 \%, 65.9 \%, 51.6 \%$ and $55.7 \%$, respectively. A significant difference was observed between gender and type of lesion (Pvalue $\leq 0.001$ ). Table 4 presents the frequencies of different intraosseous lesions.

\begin{tabular}{|c|c|c|c|c|}
\hline \multirow[t]{2}{*}{ Lesion Type } & \multicolumn{4}{|c|}{ Radiographic View } \\
\hline & Radiolucent & Radiopaque & Mixed & Total \\
\hline Inflammatory & $14(100.0)$ & $0(0.0)$ & $0(0.0)$ & $14(100.0)$ \\
\hline Cystic & $153(98.7)$ & $1(6.0)$ & $1(6.0)$ & $155(100.0)$ \\
\hline Benign tumors & $31(70.5)$ & $2(4.5)$ & $11(25.0)$ & $44(100.0)$ \\
\hline Malignant tumors & $13(68.4)$ & $0(0.0)$ & $6(31.6)$ & $19(100.0)$ \\
\hline Manifestations of bone diseases in jaws & $36(69.2)$ & $4(7.7)$ & $12(23.1)$ & $52(100.0)$ \\
\hline Total & $247(87.0)$ & $7(2.5)$ & $30(10.6)$ & $284(100.0)$ \\
\hline
\end{tabular}


Jamshidi S et al.

\begin{tabular}{|c|c|c|c|c|c|c|c|c|}
\hline \multirow[t]{2}{*}{ Lesion Type } & \multicolumn{8}{|c|}{ Age, $y$} \\
\hline & Under 10 & $11-20$ & $21-30$ & $31-40$ & $41-50$ & $51-60$ & Over 60 & Total \\
\hline Inflammatory & $0(0.0)$ & $3(21.4)$ & $4(28.6)$ & $3(21.4)$ & $3(21.4)$ & $1(7.1)$ & $0(0.0)$ & $14(100)$ \\
\hline Cystic & $12(7.7)$ & $34(21.9)$ & $49(31.6)$ & $27(17.4)$ & $19(12.3)$ & $6(3.9)$ & $8(5.2)$ & $155(100)$ \\
\hline Benign tumors in jaws & $6(13.6)$ & $12(27.3)$ & $13(29.5)$ & $7(15.9)$ & $2(4.5)$ & $1(2.3)$ & $3(6.86)$ & $44(100)$ \\
\hline Malignant tumor in jaws & $1(5.3)$ & $6(31.6)$ & $2(10.5)$ & $4(21.1)$ & $1(5.3)$ & $4(21.1)$ & $1(5.3)$ & $19(100)$ \\
\hline Manifestations of bone diseases in jaws & $4(7.7)$ & $14(26.9)$ & $15(28.8)$ & $10(19.2)$ & $6(11.5)$ & $1(1.9)$ & $2(3.8)$ & $52(100)$ \\
\hline Total & $23(8.1)$ & $69(24.3)$ & $83(29.2)$ & $51(18.0)$ & $31(10.9)$ & $13(4.6)$ & $14(4.9)$ & $284(100)$ \\
\hline
\end{tabular}

a Data are presented as No. (\%).

b Chi square $=25.1$, degrees of freedom $(\mathrm{df})=24$ and Pvalue $=0.432$; the relationship was not statistically significant.

Table 3. Frequencies of Different Intraosseous Lesions Biopsied in the Maxillofacial Region in Terms of Different Gender Groups Separately for Each Lesion Type ${ }^{\text {a,b }}$

\begin{tabular}{|c|c|c|c|}
\hline \multirow[t]{2}{*}{ Lesion Type } & \multicolumn{3}{|c|}{ Radiographic View } \\
\hline & Female & Radiopaque & Total \\
\hline Inflammatory & $12(85.7)$ & $2(14.3)$ & $14(100.0)$ \\
\hline Cystic & $70(45.2)$ & $85(54.8)$ & $155(100.0)$ \\
\hline Benign tumors & $20(45.5)$ & $24(54.5)$ & $44(100.0)$ \\
\hline Malignant tumors & $8(42.1)$ & $11(57.9)$ & $19(100.0)$ \\
\hline Manifestations of bone diseases in jaws & $28(54.9)$ & $24(45.1)$ & $52(100.0)$ \\
\hline Total & $138(48.8)$ & $146(51.2)$ & $284(100.0)$ \\
\hline
\end{tabular}

a Data are presented as No. (\%).

$\mathrm{b}$ chi-squa $\mathrm{r}=9.6$, degrees of freedom $(\mathrm{df})=4$ and $\mathrm{P}$ value $=0.045$.

Table 4. Frequencies of Different Intraosseous Lesions Biopsied in the Maxillofacial Region of Patients Referring to all the Educational Pathology Centers of Hamadan Province From 1990 to $2010^{a}$

\begin{tabular}{|c|c|c|c|c|c|c|c|}
\hline Lesion & Frequency $^{b}$ & Mean Age, y & $\begin{array}{c}\text { Female } \\
\text { Frequency }\end{array}$ & $\begin{array}{c}\text { Male } \\
\text { Frequency }\end{array}$ & $\begin{array}{c}\text { Radiolucent } \\
\text { Frequency }\end{array}$ & $\begin{array}{c}\text { Radiopaque } \\
\text { Frequency }\end{array}$ & $\begin{array}{c}\text { Mixed } \\
\text { Frequency }\end{array}$ \\
\hline Radicular cyst & $51(17.8)$ & 33.3 & 25 & 26 & 51 & 0 & 0 \\
\hline ОКС & $45(15.7)$ & 30.3 & 17 & 28 & 45 & 0 & 0 \\
\hline Dentigerous cyst & $26(9.1)$ & 27.1 & 13 & 13 & 26 & 0 & 0 \\
\hline CGCG & $22(7.7)$ & 26.8 & 10 & 12 & 22 & 0 & 0 \\
\hline Ameloblastoma & $21(7.3)$ & 32.4 & 10 & 11 & 21 & 0 & 0 \\
\hline Infected odontogenic cyst & $19(6.6)$ & 22.7 & 6 & 13 & 19 & 0 & 0 \\
\hline Osteosarcoma & $12(4.2)$ & 31.8 & 6 & 6 & 9 & 0 & 3 \\
\hline Periapical granuloma & $11(3.8)$ & 33.5 & 5 & 6 & 11 & 0 & 0 \\
\hline Central ossifying fibroma & $11(3.8)$ & 32.8 & 10 & 1 & 4 & 0 & 7 \\
\hline Calcifying odontogenic cyst & $7(2.4)$ & 24.1 & 5 & 2 & 5 & 1 & 1 \\
\hline Chondrosarcoma & $6(2.1)$ & 35.0 & 2 & 4 & 3 & 0 & 3 \\
\hline Odontoma & $5(1.7)$ & 14.0 & 2 & 3 & 1 & 0 & 4 \\
\hline Osteoma & $5(1.7)$ & 22.0 & 3 & 2 & 0 & 2 & 3 \\
\hline Aneurysmal bone cyst & $5(1.7)$ & 24.0 & 4 & 1 & 5 & 0 & 0 \\
\hline Traumatic bone cyst & $4(1.4)$ & 22.0 & 3 & 1 & 4 & 0 & 0 \\
\hline Adenomatoid odontogenic tumor & $4(1.4)$ & 30.5 & 2 & 2 & 2 & 0 & 2 \\
\hline Fibrous dysplasia & $4(1.4)$ & 28.3 & 3 & 1 & 1 & 3 & 0 \\
\hline Central hemangioma & $4(1.4)$ & 14.0 & 0 & 4 & 4 & 0 & 0 \\
\hline Cemento-osseous dysplasia & $4(1.4)$ & 29.5 & 4 & 0 & 1 & 0 & 3 \\
\hline Residual cyst & $3(1.0)$ & 35.7 & 1 & 2 & 3 & 0 & 0 \\
\hline Nasopalatine duct cyst & $3(1.0)$ & 39.0 & 1 & 2 & 3 & 0 & 0 \\
\hline Focal cement osseous dysplasia & $3(1.0)$ & 33.0 & 1 & 1 & 0 & 1 & 2 \\
\hline Osteomyelitis & $3(1.0)$ & 26.0 & 2 & 1 & 3 & 0 & 0 \\
\hline Calcifying epithelial odontogenic tumor & $2(0.7)$ & 28.5 & 0 & 2 & 1 & 0 & 1 \\
\hline Cherubism & $2(0.7)$ & 13.0 & 1 & 1 & 2 & 0 & 0 \\
\hline Osteoblastoma & $1(0.3)$ & 35.0 & 1 & 0 & 0 & 0 & 1 \\
\hline Myxoma & $1(0.3)$ & 19.0 & 1 & 0 & 1 & 0 & 0 \\
\hline Central odontogenic fibroma & $1(0.3)$ & 11.0 & 1 & 0 & 1 & 0 & 0 \\
\hline Eosinophilic granuloma & $1(0.3)$ & 28.0 & 0 & 1 & 1 & 0 & 0 \\
\hline Squamous cell carcinoma & $1(0.3)$ & 42.0 & 0 & 1 & 1 & 0 & 0 \\
\hline Total & $287(100 \%)$ & 29.06 & 139 & 147 & 250 & 7 & 30 \\
\hline
\end{tabular}

a Abbreviations: OKC, odontogenic keratocyst; CGCG, central giant cell granuloma.

b Data are presented as No.(\%). 


\section{Discussion}

Intraosseous lesions consist of a wide range of lesions. In the present study, 287 intraosseous lesions were found among all the lesions evaluated, consisting of the following lesions in a descending order: cystic lesions (55.1\%), manifestations of systemic conditions in jaws (18.1\%), benign tumors (15.3\%), malignant neoplasms (6.6\%), and inflammatory lesions (9.4\%). In a study by Ali (5), the majority of lesions were cysts (55.1\%), followed by inflammatory lesions (29.9\%) and tumors (23.9\%). The majority of intraosseous lesions in that study and in the present study were cysts, demonstrating consistency between the two studies. However, in the present study, manifestations of systemic conditions in the jaws were the second most prevalent lesions; but, in the study by Ali (5) inflammatory lesions were the second most prevalent lesions. Such a disparity might be attributed to factors such as residential location, socioeconomic status, geographic location, and hygiene (5). In the present study, the majority of the lesions were radiolucent, followed by mixed and radiopaque lesions. The majority of the lesions with radiolucent radiographic view were cysts, with radicular cysts, odontogenic keratocyst (OKC) and dentigerous cysts being the most frequent ones. In a study by Tortorici et al. (1) 1273 radiolucent lesions related to odontogenic cysts were reported, the most common of which were radicular cysts, OKC and dentigerous cysts in a descending order.

In the present study, 144 odontogenic cysts were reported, the majority of which had developed in males during the third decade of life in the maxilla. In studies by Koseoglu et al. (8), Sanatkhani et al. (9), Prockt et al. (10), and Acikgoz et al. (6), 90, 58, 680 and 452 cases of odontogenic cysts were reported, respectively. Differences in the number of cases reported might be attributed to intervals, the number of patients referring to treatment factors, and some other factors. In the study by Sanatkhani et al. (9), the majority of odontogenic cysts occurred during the second decade of life in contrast with the results of the present study.

In the present study, $17.8 \%$ of the whole intraosseous lesions were radicular cysts, with a mean age of $33.3 \%$ years and an age range of 3 - 68 years. In addition, the majority of these lesions were found in males in the anterior maxilla with a radiolucent view. In studies by Tortorici et al. (1) and Koseoglu et al. (8) the majority of radicular cysts were reported in males; however, in a study by Jones et al. (11) a similar gender predilection was reported. In studies by Jones et al. (11), Koseoglu et al. (8), and Acikgoz et al. (6) the most common location for the radicular cysts was the anterior maxilla, consistent with the results of the present study. Jones et al. (11) and Prockt et al. (10) reported that these cysts developed most commonly in the third to fourth decades of life. Koseoglu et al. reported that the majority of radicular cysts were radiolucent, consistent with the results of the present study (8). Odontogenic keratocyst in the present study comprised $15.7 \%$ of all the intraosseous lesions, ranking the second in relation to prevalence. The mean age of the patients was 30.3\% years and the majority of the lesions was located in the mandible with a radiolucent appearance and had a predilection for males.

In the study by Jones et al. (11) the prevalence of OKC was higher in males, consistent with the results of the present study. However, in the study by Koseoglu et al. (8) the prevalence of $\mathrm{OKC}$ was equal in males and females, in contrary with our results. Jones et al. (11), Koseoglu et al. (8), and Kondell and Wiberg (12) reported that the most common location for OKC was the posterior mandible, consistent with the results of the present study. The majority of OKCs in the study by Jones et al. (11) developed during the second and third decades of life. In the present study, the mean age of the patients was 29.5 years, consistent with the study above. In our study, dentigerous cysts comprised 9.1\% of intraosseous lesions with a mean age of the patients being 27.1 years, with equal occurrence in males and females in the posterior mandible with a radiolucent view, ranking the third most common cyst. Koseoglu et al. (8) and Jones et al. (11) reported a higher prevalence of dentigerous cysts in males; however, Prockt et al. (10) reported an equal prevalence rate in males and females. The results of the present study were in contrary with those of Koseoglu et al. (8) and Jones et al. (11) and consistent with those of Prockt et al. (10).

In addition, consistent with the results of the present study, all the tree studies above reported a higher prevalence of dentigerous cysts in the mandible. Since the majority of impacted teeth are mandibular third molars and such cysts are usually associated with impacted teeth, the most common site for these cysts is the posterior mandible $(8,10,11)$.

The mean age for the incidence of dentigerous cysts in the present study was the third decade of life, consistent with the mean age reported by Koseoglu et al. (8) and Prockt et al. (10) but not consistent with that reported by Jones et al. (11) i.e., the fifth decade of life. In the present study, the majority of central giant cell granulomas were reported in males with a mean age of 26.8 years and with a radiolucent view in the posterior mandible.

Mohajerani et al. (13) reported that central giant cell granuloma was the second most common giant cell lesion after peripheral giant cell granuloma. If we do not consider the peripheral lesion, in the present study, central giant cell granuloma was the most common lesion among giant cell lesions, ie, cherubism, aneurysmal bone cysts, central giant cell granuloma and Brown tumor, consistent with the study above. Motamedi et al. (14) and Mohajerani et al. (13) reported that the prevalence of central giant cell granuloma was higher in females, which was different from the results of the present study; however, the mean age of 23.72 years and the mandible were consistent with the results of the present study. In relation to fibro-osseous lesions, Alsharif et al. (15), and Worawongvasu and Songkampol (16) reported that central cemento-ossifying fibroma and 
fibrous dysplasia were the most prevalent lesions, respectively, consistent with our results.

Worawongvasu and Songkampol (16), Alsharif et al. (15), and Matsuzaka et al. (17) reported that the most common location for cemento-ossifying fibroma was the mandible, consistent with the results of the present study. The majority of these lesions were seen in females and males in studies by Matsuzaka et al. (17) and Alsharif et al. (15), respectively, inconsistent and consistent with the results of the present study, respectively. These lesions were most prevalent in the third and fourth decades of life in the study by Worawongvasu and Songkampol (16) and in the second decade of life in the study by Matsuzaka et al. (17). In the present study, the majority of these lesions developed in the third decade of life, consistent and inconsistent with the results of the first and second studies above, respectively. The majority of these lesions were radiolucent in the present study, which was not consistent with the results of Worawongvasu and Songkampol (16) who reported that the majority of these lesions were mixed (16). In the studies carried out by Worawongvasu and Songkampol (16), and Matsuzaka et al. (17), Alsharif et al. (15), the majority of fibrous dysplasia lesions were seen in the mandible, maxilla, and with equal distribution between both arches, respectively. The results of the present study were consistent with those of Matsuzaka et al. (17) and in contrary with those of the two other studies. The majority of these lesions were seen in the second decade of life in those three studies and in the third decade in the present study.

In the studies by Matsuzaka et al. (17) and Alsharif et al. (15), the majority of these lesions were seen in females and equal in but genders, respectively. The results of the present study were consistent with the first study and inconsistent with the latter. In the present study, the majority of these lesions were radiopaque, consistent with the results reported by Worawongvasu and Songkampol (16). Gunhan et al.(18), Olgac et al.(19) and Mamabol et al.(20) reported that the most common odontogenic tumor was ameloblastoma, consistent with the results of the present study. The majority of amelobastomas developed in the mandible in the present study, consistent with the results of the studies by Olgac et al. (19), Gunhan et al. (18), Mamabolo et al. (20), and Al-Khateeb and Ababneh (21) and Varkhede et al. (7). Based on the results of studies by Al-Khateeb and Ababneh (21), Varkhede et al. (7), and Mamabolo et al. (20), ameloblastoma appeared most commonly in the third, third-fourth and fourth decades of life, respectively; the results of the present study in this respect were consistent with the two first studies and inconsistent with those of the third study. Al-Khateeb and Ababneh (21) and Olgac et al. (19) reported a predilection for females and males, respectively. The results of the present study were consistent with those of Varkhede et al. (7).

The most prevalent malignant lesion in the present study was osteosarcoma. Ajura and Lau (22) reported that osteosarcoma had a predilection for males. However, Chidzonga and Mahomva reported a predilection for fe- males (23). In the present study, this lesion was equally distributed between males and females. Chidzonga and Mahomva (23) and Ajura and Lau (22), reported that osteosarcoma was most prevalent at 27 and $7-68$ years of age, respectively. In the present study, the mean age was 31.8 years, almost consistent with the first study above. The age range in the present study was $9-70$ years, almost consistent with the second study. In the study carried out by Matsuzaka et al. (17) the most common location for osteosarcomas was the mandible, consistent with the results of the present study.

In the present study, 14 lesions were inflammatory in origin, with the most prevalent lesion being the periapical granuloma. The lesion had a predilection for females and the mean age was 32.8 years; it was radiolucent and was most common in the mandible. In the studies by Tortorici et al.(1) and Stockdale and Chandler (24), this lesion had a predilection for males and females, respectively.

In addition, in the study by Tortorici et al. (1) the majority of lesions were identified in the third decade of life; in the study by Stockdale and Chandler (24) the majority of lesions were diagnosed in the fourth decade, consistent with the results of the present study.

In the present study, the majority of the lesions were identified in the mandible. In summary, the lesions in the present study were diverse and were widely distributed. Apart from some similar cases, there were disparities with the results of previous studies. Different factors such as residency, life style, socioeconomic status, geographic factors, racial factors, nutrition, hygiene, use of medications, presence of oral symptoms and signs, importance of biopsies based on the clinicians' opinions or preparation of patients, referrals for sampling, and any other factors are the reasons for differences in the results. The results did not show the true prevalence of intraosseous lesions within the general population, but simply reflected the frequency of histopathologically diagnosed lesions in an Iranian population. This study evaluated the clinical variables such as gender and age in a community; it can be used to estimate the prevalence of some conditions in the community and could have a great role in the provision of preventive and therapeutic measures; but, since some data sheets of patient were not completed, some data were missed. Therefore, we suggest that authorities complete records with accuracy, so that the researchers can conduct comprehensive studies and adopt some measures to prevent and treat many diseases.

\section{Acknowledgements}

This manuscript was based on a thesis submitted for the degree of Doctorate of Dental Surgery (thesis No. 687) in the School of Dentistry, Hamadan University of Medical Sciences, Hamadan, Iran, in 2011.

\section{Authors' Contributions}

Study concept and design: Shokoofeh Jamshidi, Setareh 
Shojaei; acquisition of data: Esmaeel Bakhtiary; analysis and interpretation of data: Shokoofeh Jamshidi, Setareh Shojaei, Ghodratollah Roshanaei; drafting of the manuscript: Shokoofeh Jamshidi, Setareh Shojaei, Shirin Modabbernia; critical revision of the manuscript for important intellectual content: Shokoofeh Jamshidi, Setareh Shojaei; statistical analysis: Ghodratollah Roshanaei; administrative, technical and material support: Hamadan University of Medical Sciences; study supervision: Shokoofeh Jamshidi, Setareh Shojaei.

\section{Funding/Support}

This research was supported by Hamadan University of Medical Sciences (thesis No. 687).

\section{References}

1. Tortorici S, Amodio E, Massenti MF, Buzzanca ML, Burruano F, Vitale F. Prevalence and distribution of odontogenic cysts in Sicily: 1986-2005. J Oral Sci. 2008;50(1):15-8.

2. White $\mathrm{CP}$, White $\mathrm{MB}$, Fox MA. Maternal fatigue and its relationship to the caregiving environment. Fam Syst Health. 2009;27(4):325-45.

3. Malaowalla AM, Silverman S, Mani NJ, Bilimoria KF, Smith LW. Oral cancer in 57,518 industrial workers of Gujarat, India. A prevalence and followup study. Cancer.1976;37(4):1882-6.

4. Becconsall-Ryan K, Love RM. Range and demographics of radiolucent jaw lesions in a New Zealand population. J Med Imaging Radiat Oncol. 2011;55(1):43-51.

5. Ali MA. Biopsied jaw lesions in Kuwait: a six-year retrospective analysis. Med Princ Pract. 2011;20(6):550-5.

6. Acikgoz A, Uzun-Bulut E, Ozden B, Gunduz K. Prevalence and distribution of odontogenic and nonodontogenic cysts in a Turkish Population. Med Oral Patol Oral Cir Bucal. 2012;14(1):e108-15.

7. Varkhede A, Tupkari JV, Mandale MS, Sardar M. Odontogenic tumors: a review of 60 cases. J Clin Exp Dent. 2010;2(40):e183-6.

8. Koseoglu BG, Atalay B, Erdem MA. Odontogenic cysts: a clinical study of 90 cases. J Oral Sci. 2004;46(4):253-7.

9. Sanatkhani M, Hoseini Zarch H, Pakfetrat A, Falaki F. Odontogenic cysts:a clinical and radiographic study of 58 cases. Aust J Basic App Sci. 2011;5(5):329-33.
10. Prockt AP, Schebela CR, Maito FD, Sant'Ana-Filho M, Rados PV. Odontogenic cysts: analysis of 680 cases in Brazil. Head Neck Pathol.2008;2(3):150-6.

11. Jones AV, Craig GT, Franklin CD. Range and demographics of odontogenic cysts diagnosed in a UK population over a 30-year period. J Oral Pathol Med. 2006;35(8):500-7.

12. Kondell PA, Wiberg J. Odontogenic keratocysts. A follow-up study of 29 cases. Swed Dent J.1988;12(1-2):57-62.

13. Mohajerani H, Mosalman M, Mohajerani SA, Ghorbani Z. Frequency of giant cell lesions in oral biopsies. J Dent Tehran Univ Med Sci. 2009;6(4):193-7.

14. Motamedi MH, Eshghyar N, Jafari SM, Lassemi E, Navi F, Abbas FM, et al. Peripheral and central giant cell granulomas of the jaws: a demographic study. Oral Surg Oral Med Oral Pathol Oral Radiol Endod. 2007;103(6):e39-43.

15. Alsharif MJ, Sun ZJ, Chen XM, Wang SP, Zhao YF. Benign fibro-osseous lesions of the jaws: a study of 127 Chinese patients and review of the literature. Int J Surg Pathol. 2009;17(2):122-34.

16. Worawongvasu R, Songkampol K. Fibro-osseous lesions of the jaws: an analysis of 122 cases in Thailand. J Oral Pathol Med. 2010;39(9):703-8.

17. Matsuzaka K, Shimono M, Uchiyama T, Noma H, Inoue T. Lesions related to the formation of bone, cartilage or cementum arising in the oral area: a statistical study and review of the literature. Bull Tokyo Dent Coll.2002;43(3):173-80.

18. Gunhan O, Erseven G, Ruacan S, Celasun B, Aydintug Y, Ergun E, et al. Odontogenic tumours. A series of 409 cases. Aust Dent J. 1990;35(6):518-22.

19. Olgac V, Koseoglu BG, Aksakalli N. Odontogenic tumours in Istanbul: 527 cases. Br J Oral Maxillofac Surg. 2006;44(5):386-8.

20. Mamabolo M, Noffke C, Raubenheimer E. Odontogenic tumours manifesting in the first two decades of life in a rural African population sample: a 26 year retrospective analysis. Dentomaxillofac Radiol.2011;40(6):331-7.

21. Al-Khateeb T, Ababneh KT. Ameloblastoma in young Jordanians: a review of the clinicopathologic features and treatment of 10 cases. J Oral Maxillofac Surg. 2003;61(1):13-8.

22. Ajura AJ, Lau SH. A retrospective clinicopathological study of 59 osteogenic sarcoma of jaw bone archived in a stomatology unit. Malays J Pathol. 2010;32(1):27-34.

23. Chidzonga MM, Mahomva L. Osteosarcoma of the jaws: a 23 year retrospective review. Cent Afr J Med. 2009;55(5-8):40-3.

24. Stockdale CR, Chandler NP. The nature of the periapical lesion-a review of 1108 cases. J Dent.1988;16(3):123-9. 